\section{Matéria \\ ISSN 1517-7076}

Revista Matéria, v. 11, n. 2, pp. 125 - 137, 2006

http://www.materia.coppe.ufrj.br/sarra/artigos/artigo10629

\title{
Qualidade Superficial de Peças de Alumínio Fundidas em Molde de Areia
}

\author{
Juan C. Campos Rubio ${ }^{(a)}$, Túlio Hallak Panzera ${ }^{(a)}$, Wagner Alves Nogueira ${ }^{(b)}$ \\ (a) Universidade Federal de Minas Gerais, Departamento de Engenharia Mecânica. \\ Av. Antonio Carlos 6627, Belo Horizonte, MG, Cep: 31.270-901 \\ (b) SENAI - Américo René Gianetti. \\ Av. Antônio Carlos 551, Lagoinha, Belo Horizonte, MG, Cep: 31.270-000 \\ e-mail: juan@ufmg.br, hallakpanzera@ig.com.br, wnogueira@fiemg.com.br
}

\begin{abstract}
RESUMO
O presente trabalho consiste basicamente na análise das características físico-químicas de areia-base para fundição e sua influência na qualidade das peças fundidas. Foram coletados cinco diferentes tipos de areia-base, ambas com o mesmo tratamento mineral. A caracterização das areias-base foi realizada através dos seguintes ensaios de laboratório: distribuição granulométrica, argila AFS, umidade, permeabilidade base, expansão ao choque térmico, perda ao fogo, temperatura de sinterização, teor de finos, caracterização visual e análise química. Foram confeccionados dois modelos diferentes. O primeiro com o formato em espiral, com o objetivo de investigar a fluidez do metal em função das características das diferentes areias-base. $\mathrm{O}$ segundo, uma placa escalonada, que permite identificar a qualidade do acabamento superficial da peça fundida para diferentes espessuras. O metal utilizado no processo de fundição foi o alumínio. A partir dos resultados encontrados no ensaio tecnológico, observou-se uma correlação com os resultados de laboratório, verificando que uma correta análise das características identificadas no laboratório permite prever o comportamento da areia-base e seu resultado final observado na peça fundida.
\end{abstract}

Palavras chaves: Areia-base (sílica), fundição de alumínio, fluidez, acabamento superficial.

\section{Surface Quality of Sand Aluminum Pieces Cost}

\begin{abstract}
The present work consists to analyze the physical and chemical characteristics of sands used to foundry and its influence in the quality of the melted pieces. Five different types of sand were collected, both with the same mineral treatment. The characterization of the sand was carried out through the following laboratory tests: grain size distribution (sieving), AFS clay content, water content, permeability, thermal expansion, loss on ignition, sinter point, fine contents meshes and chemical composition. The optical microscope was used in order to identify the geometry of the grains of sand. Two different models were made. The first one with a spiral shape was made to investigate the flow's capacity of the metal with respect the different characteristics of the sands. The second model which is a plate with different thickness was made to investigate the quality of the surface finishing of the melted pieces. The metal used in the foundry process was the aluminum. It was observed a significant correlation between the laboratory and technological results, which means that it is possible to preview the quality of melted pieces from the characteristics of the sand grains.
\end{abstract}

Keywords: Foundry sand (silica), aluminum's foundry, flowing metal, surface finishing.

\section{INTRODUÇÃO}

A moldagem em areia, apesar de sua origem remota, é ainda hoje o processo mais amplamente empregado para a obtenção de peças fundidas. A versatilidade e economia deste processo permitem a sua liderança em confronto com os demais processos existentes. Está claro que no decorrer do tempo, tanto o preparo da areia de moldagem, como os processos de moldagem, vem sendo intensamente mecanizados de modo a se enquadrarem às condições atuais da economia e tecnologia, tornando-se este o principal motivo para a realização deste trabalho [1]. 
Modernas técnicas de gestão da produção, tais como aquelas baseadas na sistemática da qualidade total, baseiam-se na prerrogativa de um conhecimento aprofundado de todas as etapas do processo produtivo e um controle rígido dos insumos utilizados, seu fluxo e efeito no sistema produtivo; como forma de garantir repetibilidade, exatidão e qualidade dos resultados, diminuindo refugos e o custo final das peças, entre outros.

No meio desta fusão entre economia e tecnologia, o fator qualidade vem se destacando cada vez mais, mostrando a importância do estudo e detalhamento de todos os processos envolvidos em qualquer setor de produção. Desta forma, este trabalho tem como objetivo estudar a qualidade das peças fabricadas de alumínio em um processo de fabricação por fundição, através da análise das características da areia-base.

A fundição vem a ser a conformação de um metal no estado líquido. Este processo consiste em aquecer o metal até que ele se funda e se transforme em um líquido homogêneo, onde então será vertido em moldes adequados, adquirindo a forma desejada. Estes moldes podem ser construídos de vários materiais, sendo o mais utilizado a areia de sílica. Esta areia chamada areia-base, é um material refratário granular e inconsolidado, com alto teor de sílica; sendo ele um dos parâmetros mais importantes e de maior influência no resultado de um processo de fundição [2, $\underline{3}]$.

A partir da análise das características físico-químicas de cinco areias para fundição (beneficiadas por uma empresa especializada neste tipo de insumo) pretendem-se determinar o melhor tipo de areia para a produção de peças pelo processo de fundição de alumínio, observando após a realização do ensaio tecnológico a qualidade das peças fundidas.

\section{COLETA DAS AREIAS A SEREM ESTUDADAS}

Para a realização deste trabalho foram identificados cinco tipos de areias de sílica de procedência da Mineração Jundu (São Paulo). As amostras foram escolhidas baseando-se nos diversos tipos de areias de sílica comercializadas pela empresa para uso no processo de fundição. As especificações das areias enviadas pela empresa foram mantidas neste trabalho, nomeadas: AN101SE, AN107SE, AN153SE, AN154SE, AN155SE. Podem-se observar na Figura 1 as fotos obtidas no microscópico óptico para as respectivas areias em estudo.
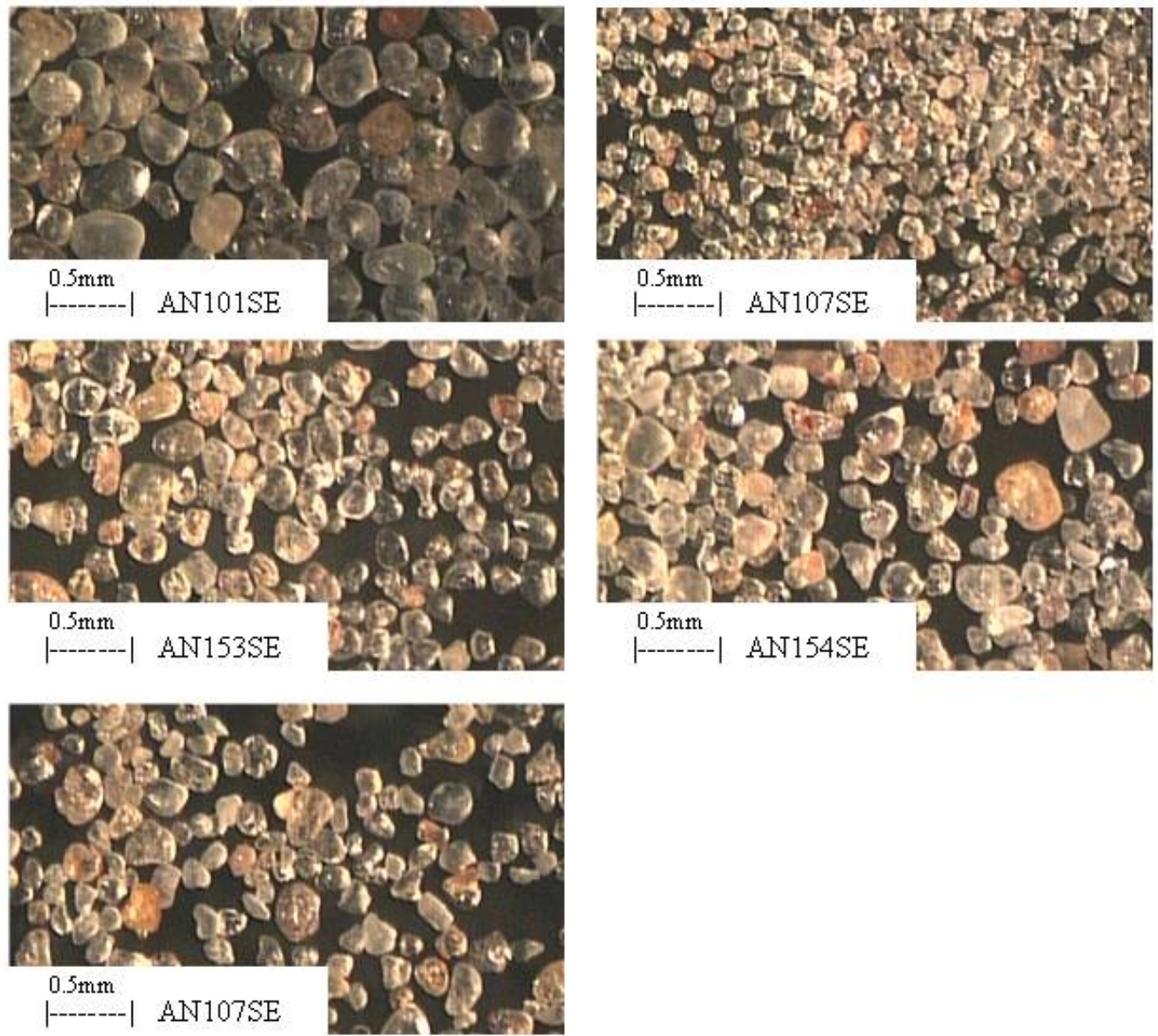

Figura 1: Aspecto macrográfico das areias analisadas. 


\section{METODOLOGIA EXPERIMENTAL}

Como forma de sintetizar a realização da parte experimental, o trabalho foi dividido em duas seções de ensaios. A primeira seção determinada pelos ensaios de laboratório, apresentando a caracterização das areias. Em uma segunda seção foram realizados os ensaios tecnológicos, permitindo comparar os resultados de laboratório e suas previsões sobre o comportamento de cada areia de sílica.

\subsection{Ensaios de Laboratório}

Dentre os diversos ensaios de laboratório possíveis de serem realizados, foram escolhidos alguns mais significativos [4]], os quais são listados abaixo:

- Distribuição granulométrica: determinação do percentual retido do material em análise em peneiras $\mathrm{N}^{\circ} 6$, 12, 20, 30, 40, 50, 70, 100, 140, 200, 270, da série ABNT, acompanhadas de prato coletor e tampa.

- Determinação da distribuição da permeabilidade da areia-base: índice que expressa a capacidade que uma areia-base possui em permitir a passagem de ar através dos vazios intergranulares sob condições padronizadas.

- Caracterização visual da forma dos grãos das areias: determinação da forma do grão através da observação das areias no microscópio óptico, fazendo sua caracterização.

- Determinação da temperatura de sinterização: temperatura na qual o material sofre início de fusão.

- Expansão por efeito de choque térmico das areias: o ensaio tem por objetivo avaliar a estabilidade térmica dimensional de uma areia.

- Determinação da perda ao fogo: determinação do teor de materiais orgânicos e de água de cristalização contidos nos constituintes do material usado, a fim de prevenir defeitos causados por gases.

- Análise química das areias: Determinação de $\mathrm{SIO}_{2} ; \mathrm{Fe}_{2} \mathrm{O}_{3} ; \mathrm{Al}_{2} \mathrm{O}_{3} ; \mathrm{TiO}_{2}$.

\subsection{Ensaio Tecnológico (Fundição)}

Para cada tipo de areia analisada serão realizados dois ensaios de fundição utilizando os dois tipos de modelos confeccionados. O primeiro modelo escalonado tem como objetivo investigar o acabamento superficial da peça em função da granulometria da areia para diferentes espessuras. O segundo modelo de formato espiral tem como objetivo estudar a fluidez do metal líquido em função da granulometria da areia do molde.

\subsection{Modelos Utilizados}

Na fundição em areia, a porosidade natural da areia permite que os gases escapem pela própria parede do molde. A maior ou menor facilidade com que o metal líquido encherá o molde dependerá de sua fluidez. O termo fluidez refere-se à propriedade de um metal líquido de poder fluir de forma livre e regular em um molde e de poder enchê-lo totalmente antes que se inicie a ação obstaculizadora da solidificação [ $\underline{5}$, 6]. Desta forma, com o objetivo em estudar a influência da areia do molde em função da fluidez do metal liquido, o modelo para confecção do molde foi projetado e construído no formato espiral (Figura 2).
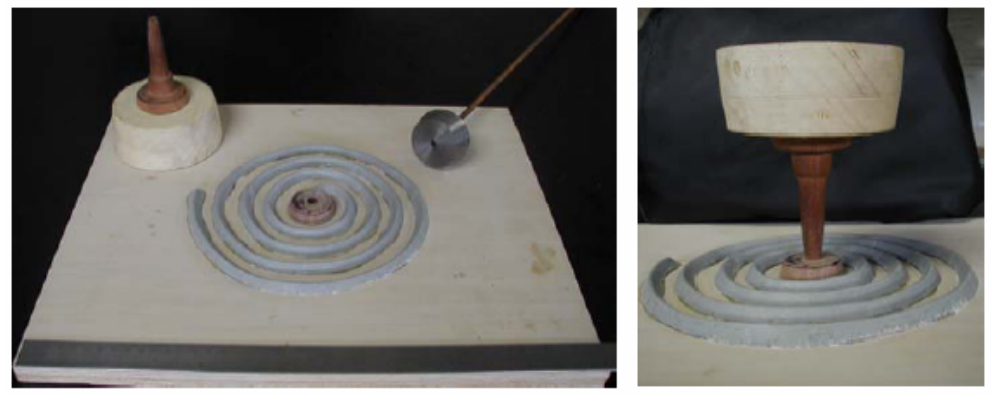

Figura 2: Modelo em espiral para ensaio de fluidez.

A Figura 3 apresenta o modelo escalonado utilizado para analisar o desempenho da areia-base no acabamento superficial da peça fundida. 


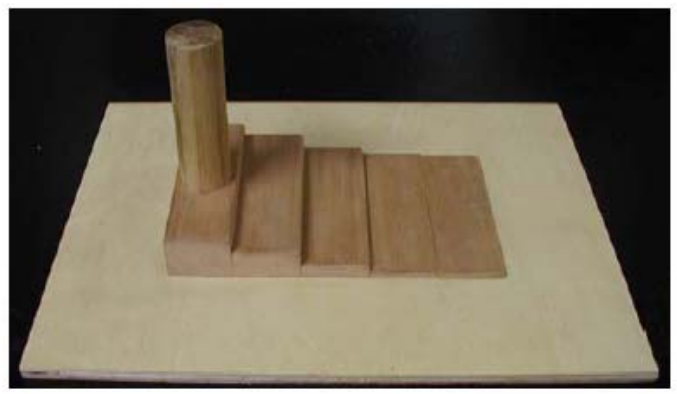

Figura 3: Modelo escalonado para analise de acabamento superficial.

Neste trabalho os moldes utilizados são do tipo fechado e descartável. A areia utilizada é a areia sintética e o material aglomerante é a bentonita. Cabe ressaltar que o enfoque do trabalho é a areia-base, mantendo desta forma durante todo o trabalho, uma porcentagem de aglomerante constante para todas as areias sintéticas e ausência de qualquer aditivo que possa alterar o desempenho da areia (e.g., pó de carvão, serragem, entre outros).

\section{PREVISÃO E ANÁLISE DOS RESULTADOS}

Neste item serão discriminados os resultados obtidos nos ensaios de laboratório (Tabela 1) e posteriormente analisados as implicâncias dos mesmos no resultado esperado dos ensaios tecnológicos.

Tabela 1: Resultados dos ensaios de laboratório realizado com as amostras.

\begin{tabular}{|c|c|c|c|c|c|c|}
\hline \multirow{2}{*}{\multicolumn{2}{|c|}{ Resultados dos ensaios }} & \multicolumn{5}{|c|}{ Referências de amostras } \\
\hline & & AN101SE & AN107SE & AN153SE & AN154SE & AN155SE \\
\hline \multicolumn{2}{|l|}{ Formato do Grão } & REDONDO & REDONDO & REDONDO & REDONDO & REDONDO \\
\hline \multicolumn{2}{|l|}{ Argila AFS (\%) } & 0,06 & 0,12 & 0,02 & 0,10 & 0,08 \\
\hline \multicolumn{2}{|l|}{ Umidade (\%) } & 0,1 & 0,1 & 0,1 & 0,1 & 0,1 \\
\hline \multicolumn{2}{|l|}{ Teor de finos (\%) } & 0 & 4,56 & 0,16 & 0,42 & 1,06 \\
\hline \multicolumn{2}{|c|}{$\begin{array}{l}\text { Percentual retido em três peneiras } \\
\text { consecutivas (\%) }\end{array}$} & 89,54 & 94,74 & 95,02 & 86,88 & 91,58 \\
\hline \multicolumn{2}{|l|}{ Módulo de finura AFS } & 43,15 & 83,22 & 55,66 & 59,78 & 69,02 \\
\hline \multicolumn{2}{|c|}{ Permeabilidade base (AFS) } & 325 & 90 & 190 & 150 & 115 \\
\hline \multicolumn{2}{|l|}{ Umidade Areia-base (\%) } & 2,28 & 1,98 & 2,08 & 2,08 & 2,08 \\
\hline \multicolumn{2}{|l|}{ Temp. Sinterização $\left({ }^{\circ} \mathrm{C}\right)$} & 1460 & 1000 & 1390 & 1200 & 1100 \\
\hline \multicolumn{2}{|c|}{ Expansão ao Choque Térmico (\%) } & 1,19 & 1,6 & 1,43 & 1,37 & 1,49 \\
\hline \multicolumn{2}{|l|}{ Perda ao Fogo (\%) } & 0 & 0 & 0 & 0 & 0 \\
\hline \multirow{5}{*}{ Análise química (\%) } & $\mathrm{PH}$ & 6,4 & 6,7 & 6,6 & 6,5 & 6,6 \\
\hline & $\mathrm{SiO}_{2}$ & 99,80 & 99,83 & 99,82 & 99,86 & 99,82 \\
\hline & $\mathrm{Fe}_{2} \mathrm{O}_{3}$ & 0,024 & 0,025 & 0,023 & 0,026 & 0,025 \\
\hline & $\mathrm{Al}_{2} \mathrm{O}_{3}$ & 0,030 & 0,025 & 0,023 & 0,026 & 0,025 \\
\hline & $\mathrm{TiO}_{2}$ & 0,010 & 0,015 & 0,013 & 0,012 & 0,010 \\
\hline
\end{tabular}




\subsection{Quanto à permeabilidade}

Os fatores que mais influenciam na permeabilidade e suas influências estão resumidas na Tabela 2 $[\underline{1}, \underline{2}, \underline{7}, \underline{9}$. Com base nos resultados dos ensaios obtidos na Tabela 1 , determinou-se a areia mais adequada para cada quesito analisado.

Tabela 2: Resumo dos fatores que mais influenciam na permeabilidade.

\begin{tabular}{l|l|l}
\hline \multicolumn{1}{c|}{ Fatores que influenciam } & Influência na permeabilidade & Areia mais adequada \\
\hline Presença de finos & Diminui a permeabilidade & AN101SE \\
\hline Tamanho de grão maior & Aumenta a permeabilidade & AN101SE \\
\hline Presença de argila & Diminui a permeabilidade & AN153SE \\
\hline Alta concentração granulométrica & Aumenta a permeabilidade & AN107SE \\
\hline Umidade da areia-base & $\begin{array}{l}\text { Aumenta a permeabilidade até um } \\
\text { ponto ótimo de água }\end{array}$ & Não existe variação \\
\hline Grãos redondos e subangulares & Aumenta a permeabilidade & Não existe variação \\
\hline Maior tempo de mistura de aglomerante & Aumenta a permeabilidade & Não existe variação \\
\hline Alto grau de compressão (socagem) & Diminui a permeabilidade & Não existe variação \\
\hline
\end{tabular}

Resultado obtido no ensaio de laboratório: através do ensaio de permeabilidade-base representado na Figura 4, observa-se que a areia que apresenta maior permeabilidade é a AN101SE. A areia com menor permeabilidade, ou seja, com maior suscetibilidade ao aparecimento de defeitos em função da retenção de gases durante o ensaio tecnológico é a areia AN107SE. Estes resultados se apresentam coerentes com a ação dos fatores que mais influenciam na permeabilidade, entre eles presença de finos e tamanhos de grão, como mostrado na Figura 4.

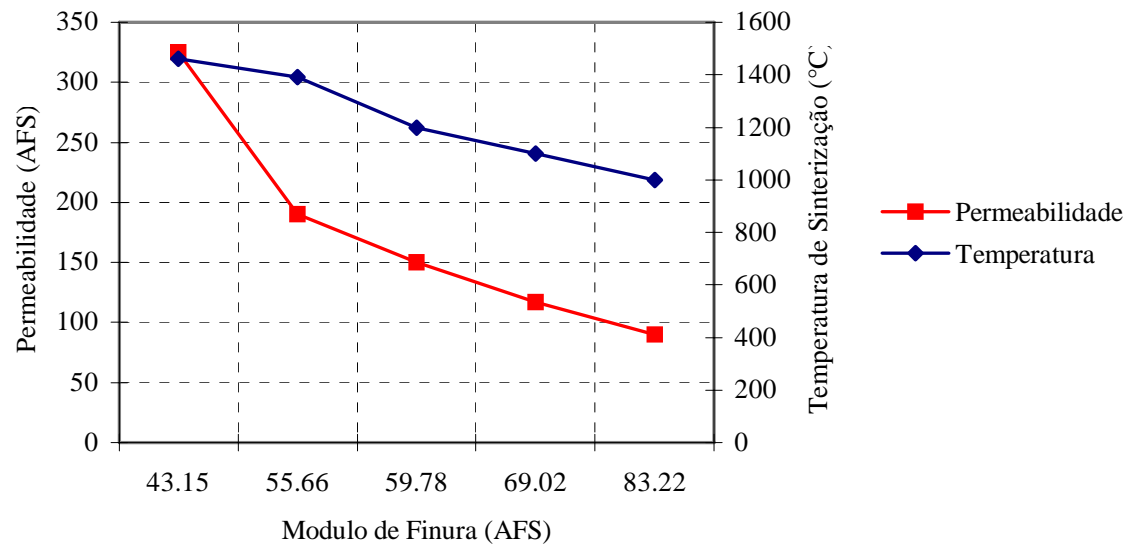

Figura 4: Resultados obtidos no ensaio de permeabilidade e temperatura de sinterização para as amostras.

Desta forma de acordo com o ensaio de permeabilidade, pode-se prever que a areia que apresentará o melhor desempenho no ensaio de fundição será a areia AN101SE. As areias AN107SE e AN155SE, poderão apresentar possíveis defeitos de fundição, devido a sua baixa permeabilidade.

\subsection{Quanto à Temperatura de Sinterização}

Os fatores que mais influenciam a temperatura de sinterização e seus modos de ação estão resumidos na Tabela $3[\underline{1}, \underline{8}]$. 
Tabela 3: Resumo dos fatores que mais influenciam no ensaio de sinterização.

\begin{tabular}{l|l|l}
\hline \multicolumn{1}{c|}{$\begin{array}{c}\text { Fatores que } \\
\text { influenciam }\end{array}$} & \multicolumn{1}{c|}{$\begin{array}{c}\text { Influência na temperatura de } \\
\text { sinterização }\end{array}$} & \multicolumn{1}{c}{ Areia mais adequada } \\
\hline Presença de feldspato & Diminui a temperatura de sinterização & Não existe presença de feldspato \\
\hline Grãos angulares & Diminui a temperatura de sinterização & $\begin{array}{l}\text { Não existe presença de grãos } \\
\text { angulares }\end{array}$ \\
\hline Grãos finos & Diminui a temperatura de sinterização & AN101SE \\
\hline
\end{tabular}

Resultado obtido no ensaio de laboratório: com base nos resultados obtidos pelo ensaio de sinterização (Figura 5), pode-se observar que a areia de melhor desempenho foi a areia AN101SE, apresentando uma temperatura de sinterização de $1460{ }^{\circ} \mathrm{C}$. Este resultado condiz com as características obtidas observadas na Tabela 1, sendo a areia com o teor mais baixo de finos.

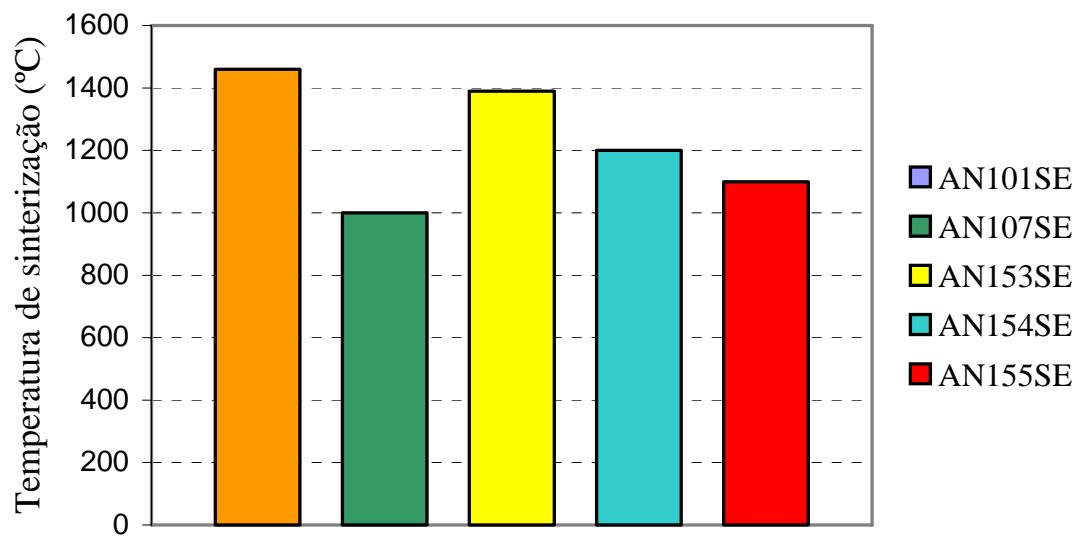

Figura 5: Resultados obtidos no ensaio de sinterização para as amostras.

De uma forma geral, todas as areias apresentaram uma temperatura de sinterização alta, mesmo porque, todas elas possuem um teor de finos muito baixos. Como não existe presença de feldspato e grãos angulares nas amostras estudadas, deve-se levar em consideração somente o teor de finos. Desta forma ,estima-se que areia que terá o melhor desempenho no ensaio de fundição será a areia AN101SE. A areia AN107SE devido possuir a menor temperatura de sinterização, poderá sofrer alguns defeitos de deformação no processo de fundição.

\subsection{Quanto à expansão ao choque térmico}

Os fatores que mais influenciam a expansão ao choque térmico e suas influências estão resumidas na Tabela $4[\underline{1}, \underline{2}, \underline{8}]$.

Tabela 4: Resumo dos fatores que mais influenciam no ensaio de expansão ao choque térmico.

\begin{tabular}{llc}
\hline Fatores que influenciam & Influência na expansão ao choque térmico & Areia mais adequada \\
\hline Presença de finos & Diminui a expansão ao choque térmico & AN107SE \\
\hline Tamanho de grão menor & Aumenta a expansão ao choque térmico & AN101SE \\
\hline Impurezas & Diminui a expansão ao choque térmico & Não existe variação \\
\hline Grãos redondos & Aumenta a expansão ao choque térmico & Não existe variação \\
\hline Alta concentração granulométrica & Aumenta a expansão ao choque térmico & AN153SE \\
\hline
\end{tabular}


Resultado obtido no ensaio de laboratório: observando-se o gráfico da Figura 6, pode-se concluir que areia que obteve uma menor expansão ao choque térmico foi a areia AN101SE. Isto pode ser comprovado pelo fato dela possuir grãos de tamanho maiores.

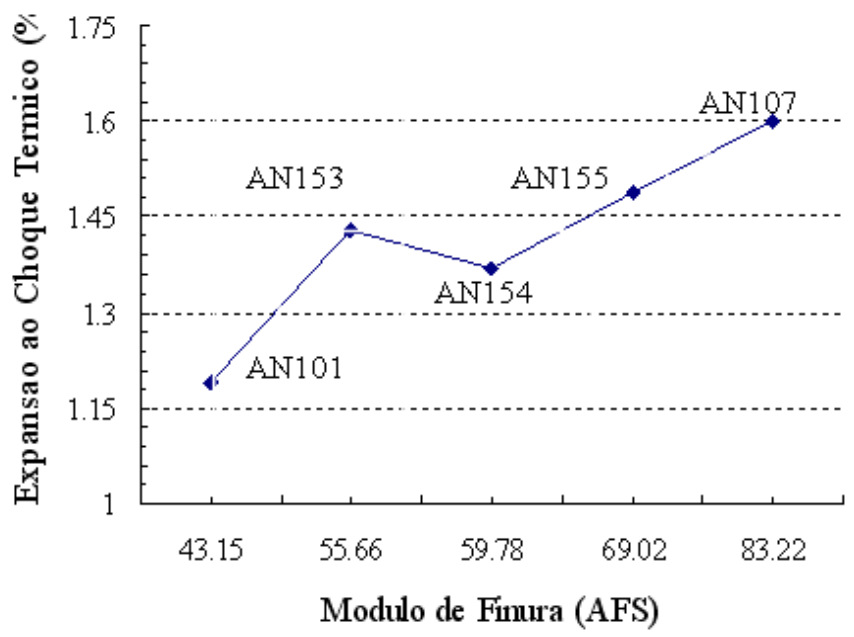

Figura 6: Resultados obtidos no ensaio de expansão ao choque térmico.

Cabe ressaltar que a variação dos valores dos resultados obtidos é muito pequena e que, entre os fatores que mais influenciam a expansão ao choque térmico, as areias AN107SE e AN153SE, apesar de não apresentarem resultados condizentes com a teoria, apresentam fatores relevantes, como, alta presença de finos e baixa concentração granulométrica, respectivamente. Assim, a areia tipo AN101SE possui grande probabilidade de apresentar o melhor desempenho no ensaio de fundição, devido apresentar resultados satisfatórios no ensaio de laboratório, como também nos fatores de mais influência como tamanho de grão maior.

\subsection{Quanto à Granulometria}

A granulometria das partículas de sílica afeta principalmente na condutividade do molde e no acabamento superficial (Tabela 5). Desta forma, pode-se dizer que a areia mais adequada para se atingir o melhor desempenho em um ensaio de fundição é aquela que possui grãos menores, proporcionando melhor acabamento superficial da peça fundida e maior condutividade térmica para resfriamento da mesma [1, 4$]$. Assim, pode-se prever o comportamento do ensaio de fundição em função da granulometria da areia.

Tabela 5: Resumo das características mais influenciadas pela granulometria.

\begin{tabular}{cc}
\hline Granulometria & Características influenciadas \\
\hline Menor tamanho de grão & Maior condutividade do molde \\
\hline Menor tamanho de grão & Melhor acabamento superficial \\
\hline
\end{tabular}

Os resultados obtidos de módulo de finura para cada areia são apresentados graficamente na Figura 7, onde verifica-se que a areia que terá menores tamanhos de grãos será AN107SE, diferente da areia AN101SE que possui um módulo de finura baixo, com tamanhos de grãos maiores e conseqüentemente apresentando acabamento superficial mais grosseiro. 


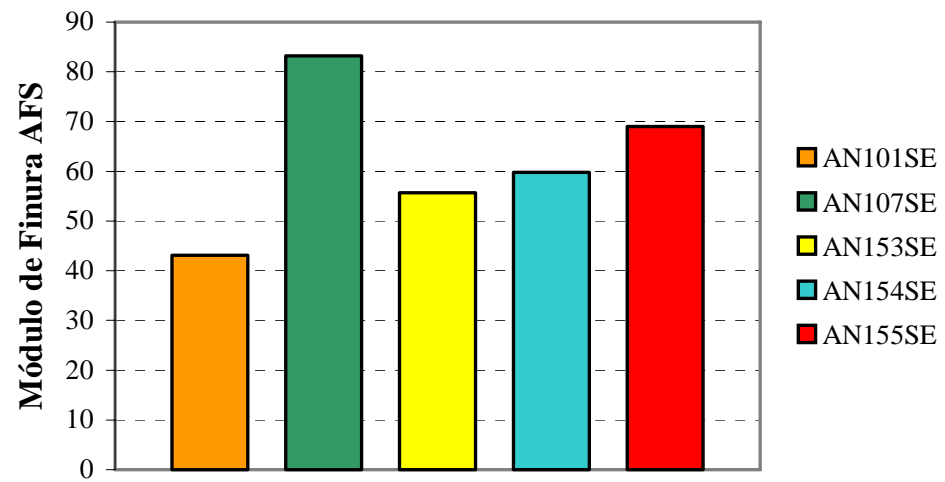

Figura 7: Resultados do Módulo de Finura.

\subsection{Quanto à caracterização visual}

Todas as amostras investigadas neste trabalho possuem um formato de grão redondo. A Tabela 6 apresenta as principais características que possuem efeito significante quanto à forma da partícula, entre elas, moldação, permeabilidade e uso de aglomerantes. Da mesma forma, é relevante salientar as tendências no aumento da expansão ao choque térmico e arraste de areia com o fluxo do metal []ㅡ. Desta forma, pode-se prever a existência de alguns defeitos apresentados na fundição, como alterações na geometria e na dimensão da peça fundida.

Tabela 6: Resumo das características mais influenciadas pelo formato do grão.

\begin{tabular}{ll}
\hline \multicolumn{1}{c}{ Formato de grão } & \multicolumn{1}{c}{ Características influenciadas } \\
\hline Grão redondo & Aumenta a aptidão à moldação \\
\hline Grão redondo & Requer menor quantidade de aglomerantes \\
\hline Grão redondo & Permeabilidade não é afetada com a socagem \\
\hline Grão redondo & Aumenta a expansão ao choque térmico \\
\hline Grão redondo & Tendência de a areia ser arrastada pelo fluxo de metal fundido \\
\hline Formato uniforme & Menor coesão \\
\hline
\end{tabular}

\subsection{Quanto à distribuição granulométrica}

As características que possuem maior efeito quanto à distribuição granulométrica estão resumidas na Tabela 7. Denomina-se "concentração granulométrica" o valor máximo percentual retido em três peneiras consecutivas da série padrão. A sua distribuição granulométrica com mais de $50 \%$ e menos de $70 \%$ de grãos retidos em três peneiras consecutivas da série padrão, resulta em melhor permeabilidade e baixa expansão conforme é demonstrado na prática $[\underline{4}, \underline{9}, \underline{10}]$. Areias com alta concentração granulométrica apresentam alta permeabilidade, devido ao grande número de espaços intergranulares, geralmente vazios. Os resultados obtidos da distribuição granulométrica estão apresentados no gráfico da Figura 8.

Tabela 7: Resumo das características mais influenciadas pela distribuição granulométrica.

\begin{tabular}{ll}
\hline \multicolumn{1}{c}{ Distribuição granulométrica } & \multicolumn{1}{c}{ Características influenciadas } \\
\hline Concentrada & Aumenta a escoabilidade (fluidez) \\
\hline Concentrada & Alta expansão ao choque térmico \\
\hline Concentrada & Alta permeabilidade \\
\hline
\end{tabular}




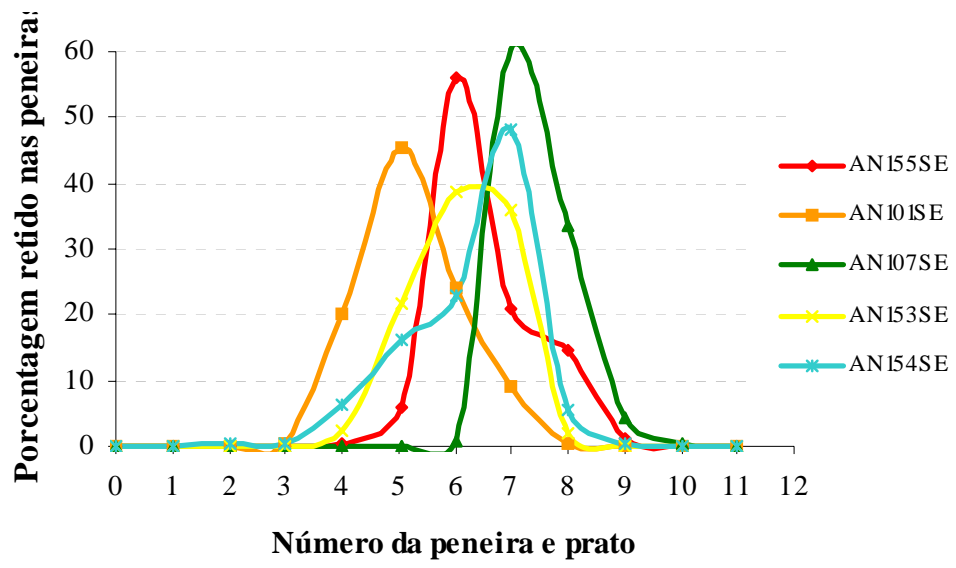

Figura 8. Resultados obtidos no ensaio de distribuição granulométrica.

Pode-se constatar que ambas as areias possuem uma boa distribuição granulométrica concentrada. A Tabela 8 apresenta o valor percentual retido em três peneiras consecutivas. É possível prever uma alta permeabilidade, como também uma alta expansão ao choque térmico, e assim trazer possíveis defeitos de fundição com relação à dimensão da geometria da peça.

Tabela 8: Percentual retido em três peneiras consecutivas.

\begin{tabular}{ccc}
\hline Tipo de areia & Três peneiras consecutivas (ABNT) & Percentual retido (\%) \\
\hline AN101SE & {$[40,50,70]$} & 89,54 \\
\hline AN107SE & {$[70,100,140]$} & 94,74 \\
\hline AN153SE & {$[50,70,100]$} & 95,02 \\
\hline AN154SE & {$[50,70,100]$} & 86,88 \\
\hline AN155SE & {$[70,100,140]$} & 91,58 \\
\hline
\end{tabular}

\section{RESULTADOS DOS TESTES TECNOLÓGICOS}

O processo de preparação da mistura areia de sílica, bentônica e água, como também a etapa de moldagem seguiu as recomendações da ABIFA. Os ensaios tecnológicos de fundição foram realizados no laboratório de "Fundição e Solidificação de Metais", do departamento de engenharia metalúrgica da UFMG. Foi utilizado um forno elétrico para a fusão do metal alumínio.

Uma vez que o metal líquido tenha sido descarregado do forno de fusão, tem-se um curto espaço de tempo para iniciar-se a solidificação no molde. Operações rápidas são premiadas para o sucesso na obtenção de produtos fundidos de qualidade. Levando em conta a temperatura final para o vazamento e as perdas de calor na transferência do cadinho (panela de vazamento), escolheu-se uma temperatura do metal acima de seu ponto de fusão a $800^{\circ} \mathrm{C}$, concedendo uma folga para estas perdas. Antes de iniciar o vazamento foi utilizado um pirômetro (Ray Tec modelo-IS8), aparelho usado para medir temperaturas através de sensor infravermelho. A diminuição da temperatura é observada no visor digital do pirômetro, quando a temperatura do metal líquido alcança $730^{\circ} \mathrm{C}$, inicia-se o vazamento, permitindo assim uma temperatura constante em todos os ensaios.

\subsection{Fundição do Modelo em Espiral}

A Figura 9 mostra o resultado da aplicação do ensaio de fluidez para cada um dos cinco tipos de areia analisadas, com um volume de $30 \mathrm{dm}^{3}$ e uma altura de $60 \mathrm{~mm}$ a uma temperatura de vazamento de $730^{\circ} \mathrm{C}$. Pode-se observar que as areias com módulo de finura menor apresentaram menor fluidez (AN107SE e 
AN155SE). Isto pode ser atribuído a ação obstaculizadora que cada areia exerce sobre a fluidez do metal líquido, ou seja, a intensidade do atrito entre a parede do molde e o metal líquido. Desta forma as areias mais grossas provocam um atrito maior diminuindo a fluidez do metal e provocando conseqüentemente uma espiral menor.

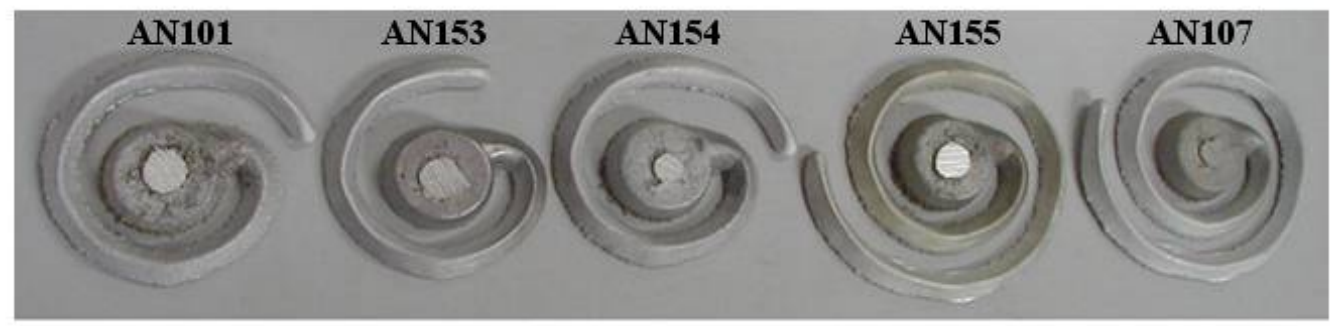

Figura 9: Resultado do ensaio de fluidez através de molde espiral.

\subsection{Fundição do Modelo Escalonado}

O acabamento superficial em peças fundidas será analisado através da variação da espessura da peça em função das características físico químicas da areia utilizada no molde de fundição. Partindo deste princípio, o modelo escalonado proporcionará a observação e a análise destes parâmetros de uma forma rápida e direta. Os resultados das peças fundidas estão apresentados na Figura 10.

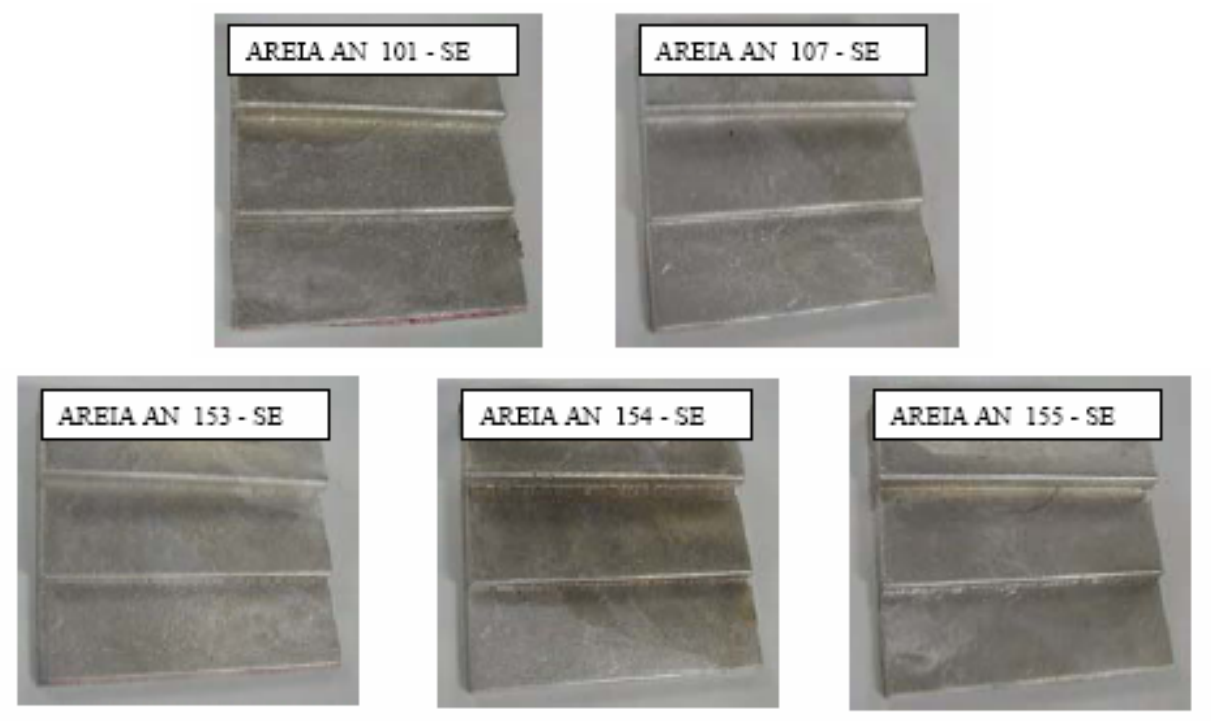

Figura 10: Aspecto da superfície da peça fundida escalonada

Por meio de um rugosímetro Mitutoyo (Surftest 301, series 178), foram obtidos os valores de rugosidade superficial. Dentre os diversos valores de rugosidade possíveis de serem analisados, foram escolhidos dois fatores mais utilizados, o fator $R_{a}$ e o fator $R_{t}$

- $\quad \mathrm{O}$ fator $\mathrm{R}_{\mathrm{a}}$ representa a média aritmética dos valores absolutos da divergência de perfil da linha de centro dentro do limite de duração de avaliação [11].

- $\quad \mathrm{O}$ fator $\mathrm{R}_{\mathrm{t}}$ representa a distância entre o pico mais alto e o vale mais fundo do perfil de aspereza dentro do limite de duração de avaliação [11].

Os resultados de rugosidade obtidos em função da espessura para as diferentes amostras podem ser observados na Figura 11. 


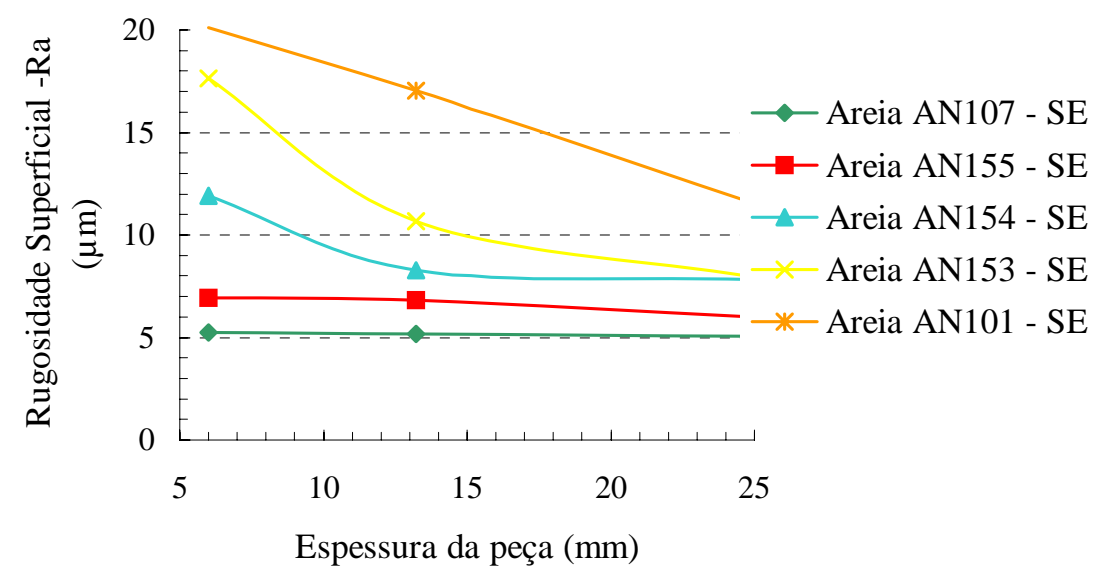

(a)

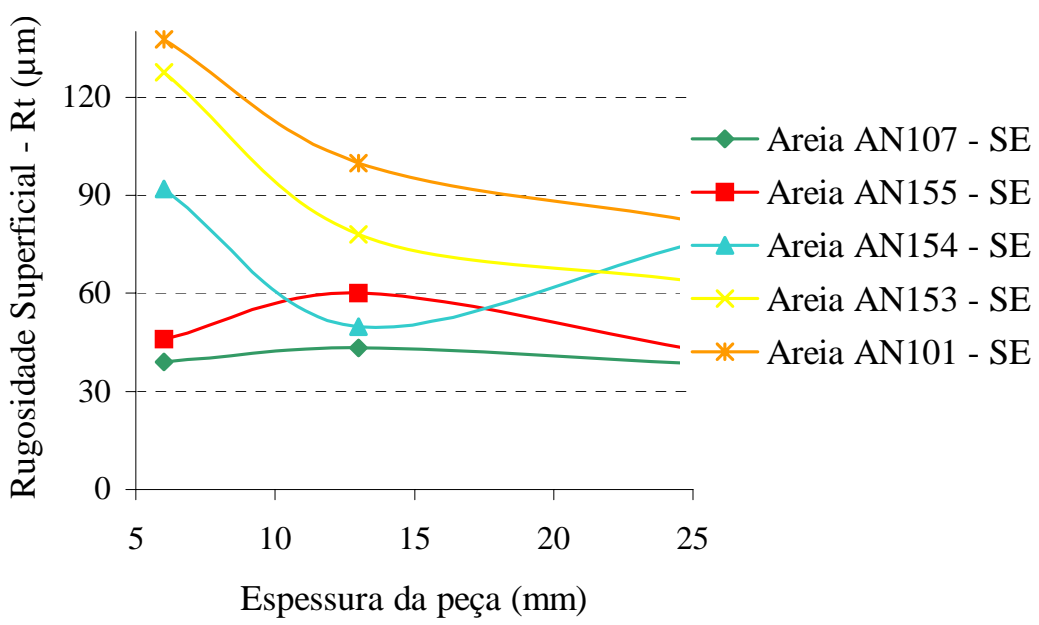

(b)

Figura 11: Gráfico da Rugosidade superficial em função da espessura da peça para diferentes areias

(a) Fator $\mathrm{R}_{\mathrm{a}} \mathrm{e}$ (b) Fator $\mathrm{R}_{\mathrm{t}}$.

De acordo com a análise dos ensaios de laboratório, pode-se afirmar que os resultados obtidos para o acabamento superficial estão condizentes com o esperado. Uma vez que, ao considerar o módulo de finura das areias, pode-se observar um melhoramento do acabamento superficial à medida que o módulo de finura aumenta, ou seja, as areias com grãos mais finos apresentaram uma rugosidade superficial menor, concordando com a teoria encontrada na literatura $[\underline{5}, \underline{6}, \underline{12}]$.

Outro aspecto observado nos gráficos da Figura 11a é que o acabamento superficial varia com a espessura da peça fundida, apresentando um melhor resultado para as espessuras mais grossas, um fator $R_{a}$ menor, melhorando o acabamento superficial. De acordo com [13], para espessuras maiores o acabamento superficial da peça fundida tende a melhorar, devido ao aumento da seção do molde, conseqüentemente a diminuição da tensão superficial.

Segundo Campbell [13], em uma série clássica de experiências demonstrou que quando a pressão no metal líquido fica suficientemente alta, a tensão superficial não é capaz o bastante de resistir à penetração do metal nos espaços entre os grãos de areia do molde. A penetração no molde deste modo produz uma fundição de textura mais áspera que pode ser totalmente descartada. A penetração pode acontecer somente na profundidade de um único grão dando efetivamente uma superfície excessivamente áspera. Os tamanhos dos 
vazios entre os grãos de areia podem ser grosseiramente estimados, assumindo que o tamanho dos espaços entre grãos deve ser aproximadamente $15,4 \%$ do tamanho do raio dos grãos de areia.

Levando em consideração a definição do fator $R_{t}$, sendo a distância entre o pico mais alto e o vale mais fundo do perfil de aspereza dentro do limite de duração de avaliação, pode-se identificar na Figura 11b o comportamento de cada areia quanto a aptidão à moldação. Observa-se que a areia AN107 apresentou o menor valor de $\mathrm{R}_{\mathrm{t}}$, sendo esta a areia com maior modulo de finura, como também maior concentração de grãos em três peneiras consecutivas, satisfazendo as condições de moldagem.

De acordo com [12] uma areia com alta concentração granulométrica em três peneiras satisfaz as condições de moldagem. Devido este fator ser bastante igual para ambas as areias, será analisado a concentração granulométrica em uma única peneira. Estes dados podem ser observados na Tabela 9.

Tabela 9: Porcentagens da concentração granulométrica em uma peneira.

\begin{tabular}{cccccc}
\hline Tipo da areia & AN107-SE & AN155-SE & AN154-SE & AN153-SE & AN101-SE \\
\hline Peneira concentrada (MESH) & 100 & 70 & 100 & 70 & 70 \\
\hline Porcentagem concentrada (\%) & 60,48 & 56,18 & 48,12 & 38,80 & 23,96 \\
\hline
\end{tabular}

Uma maior porcentagem de areia concentrada em uma única peneira determina uma areia com uma maior quantidade de grãos do mesmo tamanho. Esta característica, de acordo com a teoria, indica uma areia com baixa capacidade de moldação, apesar de proporcionar um melhor acabamento superficial [10, 12]. Este fenômeno pode ser observado junto ao gráfico da Figura 11b, no qual mostra as amplitudes de $R_{t}$ para as diferentes areias e espessuras. Aparentemente, analisando as espessuras médias das peças, os resultados do gráfico mostram-se coerentes com a Tabela 9, apresentando um melhor acabamento para porcentagens de concentrações granulométricas maiores. Nota-se apenas uma variação para a areia AN154SE, a qual possui um melhor acabamento em sua espessura média, neste caso ainda melhor do que a areia AN155SE que possui um módulo de finura maior, ou seja, grãos mais finos. Este fato pode ser explicado devido a areia AN154SE ser mais concentrada em uma peneira de granulometria mais fina, proporcionando um melhor acabamento superficial. Outro aspecto que deve ser levado em consideração, é a baixa expansão ao choque térmico encontrada na areia AN154SE, evitando a abertura dos grãos com o aumento da temperatura, com isso apresentando baixos valores para o fator $\mathrm{R}_{\mathrm{t}}$.

\section{CONCLUSÕES}

Este trabalho permitiu a caracterização físico-química de cinco areias silicosas disponíveis comercialmente, analisando seu desempenho quando usadas como areia-base em um processo de fundição. De acordo com os resultados obtidos pode-se ratificar a importância de se fazer um estudo das características físico-químicas de uma areia-base utilizada em um processo de fundição, permitindo realizar uma previsão dos resultados no ensaio tecnológico e dando informações na escolha da melhor areia para cada tipo de fundição.

Através do ensaio de fundição realizado com a placa escalonada, pode-se concluir que o acabamento superficial varia com a espessura da peça fundida, obtendo melhores resultados para espessuras maiores, devido à diminuição da tensão superficial. Em função das baixas temperaturas alcançadas pelo metal alumínio, não foi possível observar a dilatação térmica dos grãos do molde, não apresentando problemas de fundição (e.g. trincas, etc).

A utilização do modelo em espiral permitiu concluir que a fluidez varia, dentre outros fatores, em função da distribuição granulométrica apresentada, obtendo melhores resultados com areias mais finas, provando assim, a existência da ação obstaculisadora de atrito entre o molde e o metal liquido. Este ensaio adquire maior importância quando a peça a ser fundida apresenta detalhes e geometria complexa, já que a fluidez limita a espessura mínima dos fundidos de várias ligas.

A areia AN154SE obteve um comportamento médio para todos os ensaios de laboratório realizados, comprovando o seu bom desempenho nos resultados de fundição, tendo ao mesmo tempo boas características de moldagem, resistência mecânica e acabamento superficial, tornando-se esta a mais adequada em condições de uso industrial.

Em função de seu alto módulo de finura, a areia AN107SE apresentou a temperatura de sinterização mais baixa, seguida de uma alta expansão ao choque térmico. Mesmo assim, apresentou um ótimo acabamento superficial, sendo a areia mais recomendada para fundições mais delicadas como, por exemplo, prótese dentária, fundição de jóias e ligas com baixo ponto de fusão. 


\section{REFERÊNCIAS}

[1] FERREIRA, J.M.G.C., Tecnologia da Fundição, Fundação Calouste Gulbenkian, Lisboa, 1999.

[2] ReSende, M., Princípios de Processos de Produção, Departamento de Eng. Mecânica, Escola de Engenharia de São Carlos, USP, 1992.

[3] SIEGEL, M., Fundição, Editora da Associação Brasileira de Metalurgia e Materiais, São Paulo, 1978.

[4] MUCHON, L.G.O., “Analise de Areias para Fundição de Minas Gerais”, M.Sc. Tese, Departamento de Engenharia Metalúrgica, UFMG, 1986.

[5] PARIS, A., SCHWARTZ, C., “Analise da Fluidez de Ligas”, In: Congresso Brasileiro de Engenharia Mecânica (COBEM2001), Uberlândia, 2000.

[6] SENAI, Areias de Fundição, Departamento Regional de Minas Gerais, Centro de Fundição de Itaúna, 1987.

[7] TORRES, J., Manual Prático de Fundição, São Paulo, Hemus Livraria Ed. Ltda, 1975.

[8] ZANETTI, M.C., FIORE, S., "Foundry Processes: The Recovery of Green Moulding Sands for Core Operations”, Resources, Conservation and Recycling, v. 38, n. 3, pp. 243-254, 2003.

[9] PODOBED, D., ERSCHOV, S.,TILCH, W., EIGENFELD, K., "Problemas e Possíveis Soluções na Produção de Fundidos de Magnésio”, Revista Fundição e Serviço, pp. 4055, 2000.

[10] PANZERA, T.H., “Analise das Características Físico-Químicas de Areia para Fundição”, Trabalho de Diplomação do Curso de Engenharia Mecânica, UFMG, 2002.

[11] MITUTOYO, Surface Texture Parameters Surftest 301, Series 178, manual no 4373, Laboratório de Metrologia, Departamento de Eng. Mecânica, UFMG, 1995.

[12] OLHERO, S.M., FERREIRA, J.M.F., "Influence of Particle Size Distribution on Rheology and Particle Packing of silica-based Suspensions”, Powder Technology, v. 139, pp. 69-75, 2004.

[13] CAMPBELL, J., Castings, ed. 2, Oxford, 2003. 